\title{
Location of a Single $\beta$-Tubulin Gene Product in Both Cytoskeletal and Mitotic-spindle Microtubules in Physarum polycephalum
}

\author{
By EILEEN C. A. PAUL ${ }^{1}, \dagger$ TIMOTHY G. BURLAND ${ }^{2 *}$ and KEITH GULL ${ }^{1}$ \\ ${ }^{1}$ Biological Laboratory, University of Kent, Canterbury, Kent CT2 7NJ, UK \\ ${ }^{2}$ McArdle Laboratory, University of Wisconsin, Madison, W1 53706, USA
}

(Received 15 July 1988; revised 31 October 1988; accepted 7 November 1988)

\begin{abstract}
In the mutant BEN 210 of Physarum polycephalum several $\beta$-tubulins are detectable. $\beta 1$-tubulin is unique to the myxamoeba, $\beta 2$-tubulin is unique to the plasmodium, and the mutant $\beta 1-210$ tubulin encoded by the benD210 allele is present in both cell types. In order to analyse the subcellular distribution of the $\beta 1-210$ polypeptide, we prepared cytoskeletons from myxamoebae and mitotic spindles from plasmodia, and examined the tubulin polypeptide composition of these microtubular organelles by two-dimensional gel electrophoresis and immunoblotting. The results show that the $\beta 1-210$ tubulin is present in microtubules of both the cytoskeleton and the intranuclear mitotic spindle. Thus a single $\beta$-tubulin gene product can participate in multiple microtubular organelles in distinct cellular compartments.
\end{abstract}

\section{INTRODUCTION}

Microtubules, whose principle components are $\alpha$ - and $\beta$-tubulin polypeptides, carry out a wide variety of functions in microbial eukaryotes. They form the major structural component of the mitotic and meiotic spindles, and of the cilia and flagella, organelles which mediate motility in a wide range of lower eukaryote cells. The morphology many cells adopt is a reflection of the intracellular arrangement of microtubules in concert with other cytoskeletal proteins. Additionally, many organelles and vesicles are transported intracellularly along microtubule tracks. Generally, in any one microbial cell, several of these functionally and structurally distinct microtubule types exist.

Multiple $\alpha$ - and $\beta$-tubulin isotypes exist within cells. This heterogeneity arises from some combination of multiple genes for $\alpha$-and $\beta$-tubulins, and post-translational modifications of tubulin polypeptides (Cleveland \& Sullivan, 1985). Considerable interest has developed in the tubulin composition of individual microtubular organelles, a clear question being whether the tubulin isotype composition determines the function of a microtubule (Fulton \& Simpson, 1976). One approach to this problem is to study the tubulin composition of isolated microtubular organelles.

In Physarum polycephalum, a small multi-tubulin gene family of at least three unlinked $\beta$ tubulin genes is observed (Schedl et al., 1984). The bet $A$ gene, encoding $\beta 1$ A tubulin, is expressed specifically in the amoebal phase of the life cycle; the bet $B$ gene, encoding $\beta 1 \mathrm{~B}$, is expressed in both the amoebal and plasmodial phases (Burland et al., 1984; E. Paul, unpublished observations); the bet $C$ gene encoding $\beta 2$ tubulin is expressed specifically in the plasmodial phase (Burland et al., 1988). The $\beta 1 \mathrm{~A}$ and $\beta 1 \mathrm{~B}$ tubulins are so similar (Singhofer-Wowra et al., $1986)$ that they co-migrate on two-dimensional gels, but the bet $B$-(benD210) mutant allele encodes an electrophoretically altered $\beta 1 \mathrm{~B}$-tubulin, $\beta 1 \mathrm{~B} 210$, that can be resolved from $\beta 1 \mathrm{~A}$ (Burland et al., 1984). Thus all gene products can be analysed simultaneously on the same twodimensional gel in benD210 strains.

$\nmid$ Present address: Department of Physiology, Veterinary Research Tower, Cornell University, Ithaca, NY 14853-6401, USA. 
In the cellular myxamoeba, microtubules are deployed in the cytoskeleton, mitotic spindle and centrioles (Roobol et al., 1984a). Because of the low mitotic index $(<2 \%)$, microtubules that are predominantly of cytoskeletal origin can be prepared from myxamoebal cell populations. In the plasmodium, microtubules are present only in the intranuclear mitotic spindle (Roobol et al., 1984a). Intranuclear mitosis occurs synchronously in millions of nuclei within the plasmodium, facilitating isolation of mitotic nuclei in buffers that stabilize spindle microtubules (Roobol et $a l ., 1984 b$ ). Therefore microtubules exclusively from the mitotic spindle can be analysed from the plasmodium. This report compares the different $\beta$-tubulin isotypes contained in microtubules obtained from mitotic-spindle and cytoskeleton preparations, allowing assignment of specific gene products to the distinct organelles.

\section{METHODS}

Strains of P. polycephalum. Strains CLd (Cooke \& Dee, 1975), CLd-AXE (McCullough et al., 1978), BEN210 (Burland et al., 1984) and BEN210-AXE (Foster et al., 1987) have been described. The suffix -AXE describes myxamoebal strains able to grow axenically in liquid medium. CLd-AXE and BEN210-AXE myxamoebae were used for isolation of myxamoebal cytoskeletons. CLd and BEN210 plasmodia were used for isolation of plasmodial mitotic spindles.

Cultures. Microplasmodia, synchronous macroplasmodia and axenic myxamoebae were cultured as described previously (Roobol et al., 1980, 1984b).

Isolation of mitotic nuclei. When synchronous plasmodia reached metaphase they were immediately placed in spindle stabilization buffer ( $4 \mathrm{M}$-glycerol, $10 \mathrm{~mm}$-PIPES, $5 \mathrm{mM}$-EGTA, $10 \mathrm{mM}-\mathrm{MgCl}_{2}$ and $0 \cdot 1 \%$ (v/v) Triton $\mathrm{X}-100, \mathrm{pH} 6.5$ ) at room temperature and processed as described previously (Roobol et al., 1984b).

Preparation of cytoskeletons. Myxamoebae were cultured axenically to a density of $4 \times 10^{6} \mathrm{ml}^{-1}$. A total of $2 \times 10^{7}$ cells were washed twice in $0 \cdot 1 \mathrm{M}$-PIPES, $2 \mathrm{mM}$-EGTA, $1 \mathrm{mM}-\mathrm{MgSO}_{4}, 50 \mu \mathrm{g}$ leupeptin $\mathrm{ml}^{-1}, \mathrm{pH}^{6} .9$ (PE2M1). The myxamoebal pellet was resuspended in PE2M1 with $0 \cdot 25 \%(\mathrm{v} / \mathrm{v})$ Triton $\mathrm{X}-100$ by passing it through a pipette. The cytoskeletons were then washed twice in PE2M1 buffer (modified from Clayton et al., 1982).

Immunofluorescence microscopy. Myxamoebae and plasmodia were prepared for this as described previously (Paul et al., 1987). Microtubules were detected with the anti- $\beta$-tubulin monoclonal antibody KMX-1 (Birkett et al., 1985).

Two-dimensional gel electrophoresis. In all cases the nuclear pellet, plasmodial biopsy (20 mg), myxamoebal or cytoskeletal pellet was resuspended in $50 \mu \mathrm{l}$ boiling CHES buffer $(0 \cdot 1 \mathrm{M}-\mathrm{CHES} \mathrm{pH} 9 \cdot 5,2 \%$, w/v, dithiothreitol and $5 \%, \mathrm{w} / \mathrm{v}, \mathrm{SDS})$ and boiled for $5 \mathrm{~min}$. Samples were cooled and $120 \mu \mathrm{l}$ solution $\mathrm{A}$ and $60 \mathrm{mg}$ urea were added; conditions for electrophoresis were as described previously (Burland et al., 1984).

Immunoblotting. This was done essentially as described by Towbin et al. (1979), except that Tris-buffered saline containing $0.05 \%$ Tween 20 was used for all antibody binding reactions and for saturating the binding sites of the nitrocellulose (Hancock \& Tsang, 1983), and 4-chloro-1-naphthol was used as the substrate for the horseradishperoxidase-conjugated second antibody (Dakopatts, Denmark).

The $\beta$-tubulin isotypes were identified using the monoclonal antibody KMX-1 (Birkett et al., 1985). This antibody is specific for $\beta$-tubulin, and recognises all known Physarum $\beta$-tubulins (Paul et al., 1987).

\section{RESULTS}

Pattern of $\beta$-tubulin isotypes in whole cells of wild-type $P$. polycephalum and of a $\beta$-tubulin mutant

We have used a monoclonal antibody to $\beta$-tubulin and immunofluorescence microscopy to reveal the microtubule arrays of wild-type and mutant myxamoebae and plasmodia (Fig. 1). There are no significant differences between the interphase or mitotic microtubular arrays of wild-type and mutant, indicating that the possession of the mutant $\beta$-tubulin has no deleterious effects on the cell. The mitotic indices of wild-type and mutant myxamoebae were determined from immunofluorescence micrographs made from exponentially growing cells. No significant difference was found between wild-type $(0.8 \%)$ and mutant $(1.0 \%)$, indicating that the mutant cells are able to pass through mitosis without significant delay - i.e. the mutant BEN210 appears functionally normal by this criterion also.

Wild-type myxamoebae (Fig. $2 a$ ) have a single $\beta$-tubulin electromorph designated $\beta 1$, which consists of at least two polypeptides encoded by different genes (Burland et al., 1984). The BEN210 mutant myxamoebae (Fig. $2 b$ ) have an electrophoretically normal $\beta 1(\beta 1 \mathrm{~A})$ and an altered $\beta$ tubulin, designated $\beta 1-210$. The $\beta 1-210$ tubulin is encoded by the mutant allele benD210 of the 

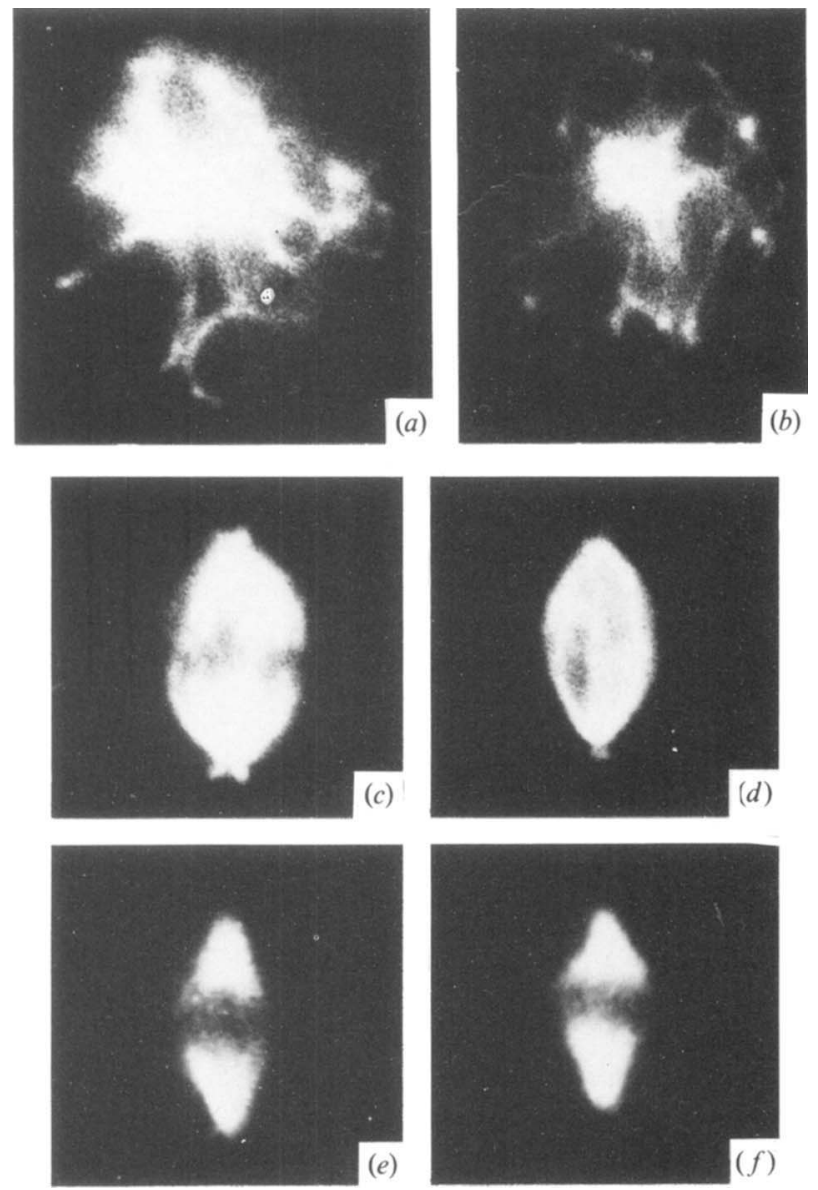

Fig. 1. Immunofluorescence images of microtubules: $(a),(c)$ and $(e)$ are the ben $D^{+}$wild-type and $(b),(d)$ and $(f)$ are the benD210 mutant. $(a)$ and $(b)$ show the microtubules of the interphase myxamoebal cytoskeleton; $(c)$ and $(d)$ show the microtubule architecture of the open myxamoebal mitotic spindle, whilst $(e)$ and $(f)$ show the microtubule arrangement of the intranuclear plasmodial mitotic spindle.

bet $B \beta$-tubulin structural gene (Burland et al., 1984). The $\beta 1-210$ polypeptide is also expressed in benD210 plasmodia, along with the plasmodium-specific $\beta 2$-tubulin, while the unaltered myxamoebal $\beta 1$-tubulin electrophoretic species observed in benD210 strains is not expressed in plasmodia (Fig. 3 b, and Burland et al., 1984).

In wild-type strains, demonstration of a single protein electromorph does not establish that the electromorph contains only a single gene product, since different genes could encode electrophoretically similar proteins. However, genetic and biochemical analysis has shown unequivocally that the $\beta 1-210$ electromorph is indeed the product of a single gene (Burland et al., 1984). The unique electrophoretic mobility of $\beta 1-210$, together with its expression in both myxamoebae and plasmodia, facilitates direct study of the presence of this single tubulin gene product in different cell types and in different microtubular organelles.

\section{Presence of $\beta 1-210$ tubulin in cytoskeletons and mitotic spindles}

To investigate the involvement of $\beta$-tubulins in different microtubular organelles, we prepared cytoskeletons from benD210 myxamoebae and purified nuclei containing metaphase spindles from benD210 plasmodia. After subjecting these preparations to two-dimensional gel 
(a)

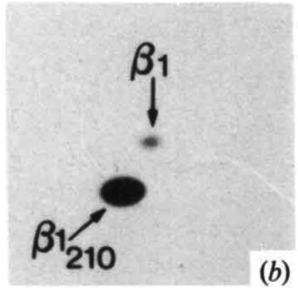

(c)

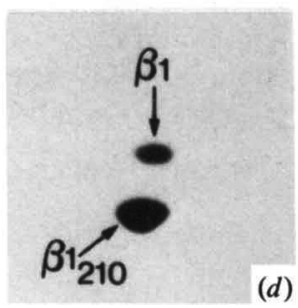

Fig. 2
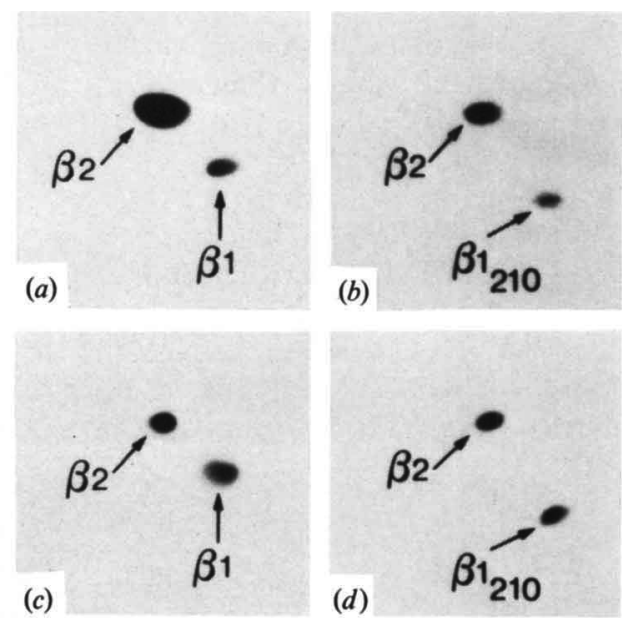

Fig. 3

Fig. 2. Detection of the $\beta$-tubulin isotypes of myxamoebae of $(a)$ the wild-type CLd-AXE strain and $(b)$ the BEN210-AXE mutant strain. The wild-type strain exhibits only one $\beta 1$ electromorph, consisting of $\beta 1 \mathrm{~A}$ and $\beta 1 \mathrm{~B}$ (Fig. $2 a$ ), whereas the BEN210 mutant strain (Fig. $2 b$ ) has $\beta 1(\beta 1 \mathrm{~A})$ and the $\beta 1-210$ electromorphs. The $\beta$-tubulin isotypes present in the interphase cytoskeletal microtubules of these myxamoebae are analysed in $(c)$ for the wild-type Cld-AXE strain and in $(d)$ for the mutant BEN210AXE strain. Panel $(d)$ reveals that the mutant $\beta 1-210$ gene product is present in the cytoplasmic microtubules of the myxamoebal cytoskeleton.

Fig. 3. Detection of $\beta$-tubulin isotypes expressed in plasmodia of $(a)$ wild-type and $(b)$ a benD210 mutant. The wild-type plasmodium expresses $\beta 1$ and $\beta 2$ isotypes whilst the mutant expresses $\beta 2$ and the $\beta 1-210$ isotypes. The $\beta$-tubulin isotypes present in the microtubules of the intranuclear mitotic spindles from the same plasmodia are analysed in $(c)$ for wild-type and in $(d)$ for the benD210 mutant. Panel $(d)$ reveals that the $\beta 1-210$ gene product is present in the microtubules of the intranuclear plasmodial spindle.

electrophoresis, the $\beta$-tubulins present were examined by immunoblotting using the anti- $\beta$ tubulin monoclonal antibody KMX-1. Analysis of the immunoblots revealed that the $\beta 1-210$ polypeptide was present in microtubules from both the plasmodial intranuclear mitotic spindle (Fig. $3 d$ ) and the myxamoebal cytoskeleton (Fig. $2 d$ ). Therefore a single $\beta$-tubulin gene product, the $\beta 1-210$ polypeptide, is located in two structurally and functionally different microtubular organelles. Since the different $\beta$-tubulins are present in the cytoskeleton and spindle preparations in a stoichiometry similar to that observed in the myxamoebal or plasmodial samples, $\beta 1-210$ tubulin seems not to be selectively enriched in either of these microtubular organelles.

These results also establish that both of the $\beta$-tubulins expressed in myxamoebae are used in the cytoskeleton, and confirm that both $\beta$-tubulin isotypes expressed in plasmodia are used in the mitotic spindle (Paul et al., 1987).

\section{DISCUSSION}

The wide variety of microtubule structures and the identification of differences in the amino acid sequences of different tubulin proteins in the same organism has led to the speculation that individual tubulin isotypes might preferentially function in different microtubule organelles (Fulton \& Simpson, 1976). As a first stage examination of this hypothesis we have analysed the tubulin isotype composition of different microtubule organelles in Physarum. The benD210 mutation allowed us to analyse simultaneously the presence of all three $\beta$-tubulin gene products in different microtubular structures. $\beta 1 \mathrm{~B}$, the one $\beta$-tubulin gene product expressed in both 
myxamoebal and plasmodial phases, is utilized not only in two different organelles cytoskeleton and spindle - but also in two different cell compartments - cytoplasm and nucleus.

Our data are in accord with results from alternative experimental approaches that indicate that multiple tubulins are used non-selectively in different microtubular organelles. In Drosophila, the B2t gene is expressed only in the testes; mutation of the B2t gene results in malfunctioning of all the microtubular organelles located in the testes (Kemphues et al., 1982). Disruption of one of the two $\alpha$-tubulin genes in yeasts (Adachi et al., 1986; Schatz et al., 1986) or the $\beta$-tubulin gene normally used in conidiation in Aspergillus (May et al., 1985; Weatherbee et al., 1985) does not prevent assembly of the usual microtubular organelles in these organisms. Transfection of various tubulin genes into cultured vertebrate cells leads to incorporation of the transfected gene product into all observable organelles (Lewis et al., 1987). Similarly, antibodies specific for individual tubulins detect each expressed tubulin isotype in all observable microtubular organelles in cultured vertebrate cells (Lewis et al., 1987; Lopata \& Cleveland, 1988).

Our analysis of isolated organelles reveals the stoichiometry of the component tubulins, information not available from the more commonly used techniques of immunofluorescent staining of specific tubulin isotypes or mutational disruption. The stoichiometry of $\beta 1 \mathrm{~A}: \beta 1 \mathrm{~B}$ in amoebae and $\beta 1 \mathrm{~B}: \beta 2$ in plasmodia was similar in whole cells and specific organelles; this suggests that the cells do not assemble a particular isotype preferentially into particular organelles, but rather that tubulins are incorporated into microtubules in the same proportions at which they are present in the tubulin pool.

Thus, overwhelming evidence has failed to reveal functional specificity for different tubulin gene products, at least at the level of utilization in distinct microtubular organelles, although it is conceivable (but perhaps unlikely) that differential utilization of individual tubulin isotypes could be observed if one examined individual microtubules. It seems most likely that the tubulin isotype composition of a microtubular organelle is not the determinant that specifies the function of the microtubule. It is plausible that tubulin is simply the main building block of the microtubule and that microtubular function is determined by other mechanisms, such as posttranslational modifications (Gard \& Kirschner, 1985; Piperno \& Fuller, 1985; Raybin \& Flavin, 1977) and involvement with microtubule-associated proteins (Parysek et al., 1984).

We thank William F. Dove for encouragement and support during the course of this work. This work was supported by grants to K. G. from the Science and Engineering Research Council. E. C. A.P. received an SERC studentship during the tenure of this work. T. G. B. is supported by the Program Project grant no. PO1-CA23076 to W. F. Dove and Core Grant no. PO3-CAO7175 to the McArdle Laboratory from the National Institutes of Health. Work between the Wisconsin and the Canterbury laboratories is supported by a Cooperative Science Program Grant no. INT-8501096 from NSF.

\section{REFERENCES}

Adachi, Y., Toda, T., Niwa, W. \& Yanagida, M. (1986). Differential expression of essential and nonessential $\alpha$-tubulin genes in Schizosaccharomyces pombe. Molecular and Cellular Biology 6, 2168-2178.

Birkett, C. R., Foster, K. E., Johnson, L. \& Gull, K. (1985). Use of monoclonal antibodies to analyze the expression of a multigene family. FEBS Letters 187, 211-218.

Burland, T. G., Schedl, T., Gull, K. \& Dove, W. F. (1984). Genetic analysis of resistance to benzimidazoles in Physarum: differential expression of $\beta$ tubulin genes. Genetics 108, 123-141.

Burland, T. G., Paul, E. C. A., Oetliker, M. \& Dove, W. F. (1988). A gene encoding the major $\beta$ tubulin of the mitotic spindle in Physarum polycephalum plasmodia. Molecular and Cellular Biology 8, 1275-1281.
Clayton, L. C., Pogson, C. I. \& Gull, K. (1982). Ultrastructural and biochemical characterization of Physarum polycephalum myxamoebae. Protoplasma 118, 181-191.

Cleveland, D. W. \& Sullivan, K. (1985). Molecular biology of tubulin. Annual Review of Biochemistry 54, $331-365$.

COOKE, D. J. \& DEE, J. (1975). Methods for the isolation and analysis of plasmodial mutants in Physarum polycephalum. Genetical Research 24, 175187.

Foster, K. E., Burland, T. G. \& Gull, K. (1987). A mutant $\beta$-tubulin confers resistance to the action of benzimidazole-carbamate inhibitors both in vivo and in vitro. European Journal of Cell Biology 163, 449455.

Fulton, C. \& Simpson, P. A. (1976). Selective 
synthesis and utilization of flagellar tubulin. The multitubulin hypothesis. In Cell Motility, pp. 9871005. Edited by R. Goldman, T. Pollard \& J. Rosenbaum. Cold Spring Harbor, NY: Cold Spring Harbor Laboratory.

GARD, D. L. \& KirschneR, M. W. (1985). A polymerdependent increase in phosphorylation of $\beta$-tubulin accompanies differentiation of a mouse neuroblastoma cell line. Journal of Cell Biology 100, 764-774.

HANCOCK, K. \& TsANG, V. C. W. (1983). India ink staining of proteins on nitrocellulose paper. Analytical Biochemistry 133, 157-162.

Kemphues, K. J., Kaufman, T. C., RafF, R. A. \& RAFF, E. C. (1982). The testis-specific beta tubulin subunit in Drosophila melanogaster has multiple functions in spermatogenesis. Cell 31, 655-670.

Lewis, S. A., Gu, W. \& Cowan, N. J. (1987). Free intermingling of mammalian $\beta$-tubulin isotypes among functionally distinct microtubules. Cell $\mathbf{4 9}$, 539-548

Lopata, M. A. \& Cleveland, D. W. (1988). In vivo microtubules are copolymers of available $\beta$-tubulin isotypes: localization of each of six vertebrate $\beta$ tubulin isotypes using polyclonal antibodies elicited by synthetic peptide antigens. Journal of Cell Biology 105, 1707-1720.

May, G. S., Gambino, J., Weatherbee, J. A. \& MORRIS, N. R. (1985). Identification and functional analysis of beta-tubulin genes by site specific integrative transformation in Aspergillus nidulans. Journal of Cell Biology 101, 712-719.

McCullough, C. H. R., Dee, J. \& Foxon, J. L. (1978). Genetic factors determining growth of Physarum polycephalum amoebae in axenic medium. Journal of General Microbiology 106, 297-306.

PARysek, L. M., Wolosewick, J. J. \& Olmsted, J. B. (1984). MAP4: a microtubule-associated protein specific for a subset of tissue microtubules. Journal of Cell Biology 99, 2287-2296.

Paul, E. C. A., Roobol, A., Foster, K. E. \& Gull, K. (1987). Patterns of tubulin isotype synthesis and usage during mitotic spindle morphogenesis in Physarum. Cell Motility and the Cytoskeleton 7, 272281.

Piperno, G. \& Fuller, M. T. (1985). Monoclonal antibodies specific for acetylated form of $\alpha$-tubulin recognize the antigen in cilia and flagella from a variety of organisms. Journal of Cell Biology 101, 2085-2094.

Raybin, D. \& Flavin, M. (1977). Modification of tubulin by tyrosylation in cells and extracts and its effects on assembly in vitro. Journal of Cell Biology 73, 492-504.

Roobol, A., Pogson, C. I. \& Gull, K. (1980). In vitro assembly of microtubule proteins from myxamoebae of Physarum polycephalum. Experimental Cell Research 130, 203-215.

Roobol, A., Paul, E. C. A., Birkett, C. R., Foster, K. E., Gull, K., Burland, T. G., Dove, W. F., Green, L., Johnson, L. \& SchedL, T. (1984 a). Cell types, microtubular organelles, and the tubulin gene families of Physarum. In Molecular Biology of the Cytoskeleton, pp. 223-234. Edited by G. G. Borisy, D. W. Cleveland \& D. Murphy. Cold Spring Harbor, NY: Cold Spring Harbor Laboratory.

Roobol, A., Paul, E. C. A. \& Gull, K. $(1984 b)$. The isolation of nuclei containing mitotic spindles from the slime mould Physarum polycephalum. European Journal of Cell Biology 33, 24-29.

Schatz, P. J., Solomon, F. \& Botstein, D. (1986). Genetically essential and nonessential $\alpha$-tubulin genes specify functionally interchangeable proteins. Molecular and Cellular Biology 6, 3722-3733.

SChedl, T., OWens, J., Dove, W. F. \& Burland, T. G. (1984). Genetics of the tubulin gene families of Physarum. Genetics 108, 143-164.

Singhofer-Wowra, M. L., Clayton, L. C., Dawson, P., Gull, K. \& Little, M. (1986). Amino acid sequence data of $\beta$-tubulin from Physarum polycephalum myxamoebae. European Journal of Cell Biology 161, 669-679.

Towbin, M., Staehelin, T. \& Gordon, J. (1979). Electrophoretic transfer of proteins from polyacrylamide gels to nitrocellulose sheets. Procedure and some applications. Proceedings of the National Academy of Sciences of the United States of America 76, $4350-4354$.

Weatherbee, J. A., May, G. S., Gambino, J. \& MORRIS, N. R. (1985). Involvement of a particular species of beta-tubulin (Beta3) in conidial development in Aspergillus nidulans. Journal of Cell Biology 101, 706-711. 